\title{
What does the future hold?
}

\author{
Fernando Peixoto Ferraz de Campos ${ }^{a}$
}

Campos FPF. What does the future hold? [editorial]. Autopsy Case Rep [Internet]. 2012;2(1):3-5.

http://dx.doi.org/ 10.4322/acr.2012.001

Since ancient times the knowledge of the human body and physiologic theories were obtained secretly, against the laws of the Catholic Church, through exhumation followed by anatomic dissection of newly buried persons. From those times, the importance of post-mortem study for the advance of medical knowledge was noted. In this context, the nineteenth century saw the heyday of the autopsy. Since then, autopsy has been responsible for the progression of clinical medicine, medical education, epidemiology, and public health. From the 1950s up until 1990, 87 diseases were identified by autopsy. The discovery of severe acute respiratory syndrome (SARS) epidemic in 2003 and the avian flu epidemic in 2006 were through autopsy as well.

Many researchers recognize the immeasurable value of autopsy for clinical, educational, epidemiological, and research purposes. Dr. Lundberg, a pathologist and former editor of JAMA, once said: "Medicine without the autopsy would not be worth being part of." The information obtained from autopsies not only instructs and confirms diagnoses, but also serves as a pathway of study and a source of investigation, a necessary tool in elucidating the changing spectrum of diseases. Autopsies have, in the past, shed light on the mechanisms of diseases that cannot be elicited in the living being and they continue to do so to this day.

Knowledge of diseases of the brain and the heart relies greatly on autopsies. Important examples include the recognition of variant Creutzfeldt-Jakob disease, delineation of Reye's syndrome, WernickeKorsakoff syndrome and thiamine deficiency, and so on. As an instrument for teaching, by correlating pathology with clinical context, autopsy remains unrivalled. Teaching based on autopsies furnish valuable skills, some of which are not easily learnt elsewhere.

Autopsies' most powerful benefit is a quality assurance instrument. The continuous study of the clinico-pathological discrepancies may show the improvement of medical care in time. The discovery of these discrepancies in the autopsy room is a powerful tool for identifying faults in medical practice and shows the need for clinical audits. Autopsy results improve death certificate accuracy. They may also alleviate the grieving process by furnishing sensitive and reasonably full information concerning the death; they may even provide the disclosure of a genetic malady, which can be investigated among the close relatives. Infectious diseases may also be detected during the autopsy that could affect family members.

Regardless of all these advantages, conversely, there is a gradual and progressive decline in the number of hospital autopsies undertaken. At present, anecdotal evidence suggests that the average non-coronial hospital autopsy rate of adult deceased is less than $10 \%$. This decline extends overseas to the east, including China and Oceania. Several reasons are speculated to explain this process that has been occurring most notably in the last 40 years. One of the main contributing factors to this decline is that clinicians do not want autopsies done. Their reasons vary from distaste for the procedure to a belief that the accuracy of modern investigative techniques avoids the need of autopsy in elucidating nothing extra to the clinical picture. The self-confidence comes mainly from the improvement in the imaging techniques and laboratory resources. Their increasing clinical

a Hospital Universitário - Universidade de São Paulo - São Paulo/SP - Brazil.

Copyright $\odot 2012$ Autopsy and Case Reports - This is an Open Access article distributed of terms of the Creative Commons Attribution NonCommercial License (http://creativecommons.org/licenses/by/3.0/) which permits unrestricted non-commercial use, distribution, and reproduction in any médium provided article is properly cited. 
confidence in the ante-mortem diagnoses supplants their need to request autopsies. This approach does not match the scientific basis, since several reports show persistent clinico-pathological discrepancies of $10-30 \%$. These discrepancies may be higher in the context of HIV, elderly patients, critically-ill patients, as well as fetus and neonate autopsies.

Paradoxically, community doctors generally show that they appreciate receiving autopsy reports and that, in a high proportion of cases, the findings are unexpected and could influence their future clinical practice. Fear of malpractice suits may also have a role in discouraging physicians to ask for post-mortem examinations. Moreover, in many instances, pathologists fail to give sufficient priority to autopsies, probably due to increasing workloads from surgical resections, biopsies, and cytology.

The continuous changes in medical school curricula results in many students graduating without ever having seen an autopsy due to competing departmental demands, limited curriculum time, and an insufficient number of hospital autopsies. How can it be expected that these future doctors may believe in the benefits of the autopsy and request it in their routine practice? Other reasons for fewer autopsy requests include the doctor's discomfort in asking for the family's consent. Doctors are not trained for, nor even convinced of, the gain of going ahead with the procedure. It is common in many institutions for the clinician to have no contact with the family before the patient's death. This makes it more difficult for a clinician to approach the family for an autopsy. We believe that obtaining consent from a family, in most cases, can be easier than expected. The family quite often feels relief with the autopsy information. In most cases the clear understanding of the disease and death process accompanied by the disclosure that nothing else could be done that would have altered the fatal evolution, promotes some comfort.

In contrast, in the UK, an increased demand for alternative procedures for post-mortem examinations due to religious objections to autopsy, among the Jewish and Muslim communities has been noticed. Therefore, post-mortem imaging was introduced with minimally invasive alternatives. Many studies try to validate this approach to the diagnosis of the cause of death in coronial autopsies. In this case, computed tomography seems to be slightly superior than magnetic resonance image. Despite the fact that radiologists can provide a cause of death accepted by the Coroner without autopsy in $90 \%$ of cases, other investigators doubt this accuracy. A major discrepancy existed in 30\% of randomly selected cases between autopsy and imaging. Due to these limitations, in the context of the determination of the cause of death, we dare to consider imaging as an auxiliary instrument to improve autopsy accuracy - but it is far from a substitute method.

Much effort and commitment is needed to reverse the declining number of autopsies trend. This reversion process involves the medical school's graduation committee, those involved in teaching programs, the pathology department of the hospital, and the hospital administration. Also, the general community needs to be better informed about the value of autopsy. It is fundamental to discuss issues related to autopsies in a similar manner to organ donations. Pathologists and clinicians as a whole should engage in measures to enhance community knowledge of the autopsy and its value. Does modern medicine still need autopsy? The answer is affirmative. If clinical autopsy rates continue to decline, the future practice of medicine will be blind to many adverse consequences of clinical actions and omissions. We advocate close communication between pathologists and clinicians in the context of the results of autopsy findings. This relationship is a strong instrument in the perpetuation of autopsy for the excellence of clinical practice. In this regard, our institution promotes weekly autopsy meetings and publishes a scientific journal with autopsy reports. In the near future, we hope to extend these meetings to other institutions by video conferences. As teachers in a teaching hospital, we still face the challenge of ensuring that medical students and residents take part in these clinico-pathological debates and sessions focused on autopsies.

\section{BIBLIOGRAPHY}

1. Roberts ISD, Benamore RE, Benbow EW, et al. Post-mortem imaging as an alternative to autopsy in the diagnosis of adult deaths: validation study. Lancet. 2012,379:136-42. http://dx.doi.org/10.1016/S0140-6736(11)61483-9

2. Zhu MH, Yu DH. Fluctuations in the rate of autopsy in China. Chin Med J. 2011;124:3403-7.

3. Xiao J, Krueger GR, Buja LM, Covinsky M. The impact of declining clinical autopsy: need for revised healthcare policy. Am J Med Sci. 2009;337:41-6. PMid:19155753. http:// dx.doi.org/10.1097/MAJ.0b013e318184ce2b 
4. Ayoub T, Chow J. The conventional autopsy in modern medicine. J R Soc Med. 2008;101:177-81. PMid:18387908. PMCid:2312379. http://dx.doi.org/10.1258/jrsm.2008.070479

5. The Royal College Of Pathologists of Australasia Autopsy Working Party. The decline of the hospital autopsy: a safety and quality issue for healthcare in Australia. Med $\mathrm{J}$ Aust. 2004;180:281-5. PMid:15012566.

6. O'Grady G. Death of the teaching autopsy. BMJ. 2003;327:802-3. PMid:14525883. PMCid:214120. http:// dx.doi.org/10.1136/bmj.327.7418.802
7. The Royal College Of Pathologists of Australasia. Autopsies and the use of tissues removed from autopsies. Document number 106581. Durham Hall; 2011 [cited 2012 Jan 10]. Available from: http://www.rcpa.edu.au/static/File/Assetlibrary/publicdocuments/PolicyManual/Policies/Autopsiesand theUseofTissuesRemovedfromAutopsies.pdf

8. Karunaratne S, Benbow EW. A survey of general practitioners' views on autopsy reports. J Clin Pathol. 1997;50:548-52. PMid:9306932. PMCid:500046. http://dx.doi.org/10.1136/ jcp.50.7.548

Correspondence: Fernando Peixoto Ferraz de Campos Scientific Editor Autopsy and Case Reports Assistant Pphysician of Internal Medicine Division Hospital Universitário - Universidade de São Paulo, São Paulo/SP - Brazil

E-mail: ffcampos@usp.br 
